\title{
Retraction Note: Precipitation anomaly in rainy season based on high resolution SAR and regulation of blood glucose in aerobic exercise for adolescents
}

\author{
Naihong Liu ${ }^{1} \cdot$ Dandan Cao ${ }^{1}$
}

Published online: 23 November 2021

(c) Saudi Society for Geosciences 2021

Retraction Note: Arabian Journal of Geosciences (2021) 14: 1762 https://doi.org/10.1007/s12517-021-08026-x

The Editor-in-Chief and the Publisher have retracted this article because the content of this article is nonsensical. The peer review process was not carried out in accordance with the Publisher's peer review policy. Author Dandan Cao has not responded to correspondence regarding this retraction. The Publisher has not been able to obtain a current email address for author Naihong Liu.

The original article can be found online at https://doi.org/10.1007/ s12517-021-08026-x.

Dandan Cao

nh_liu@126.com

1 Physical Education Department, Taiyuan University of Science and Technology, Taiyuan, Shanxi, China 